\title{
Kendali Logika Fuzzy pada Sistem Electronic Control Unit (ECU) Air Conditioner Mobil
}

\author{
Fahmizal $^{1}$, Tommy Richard Orlando 2 , Budi Bayu Murti ${ }^{3}$, Maun Budiyanto $^{4}$, Afrizal Mayub ${ }^{5}$ \\ ${ }^{1,2,3,4}$ Departemen Teknik Elektro dan Informatika, Sekolah Vokasi, Universitas Gadjah Mada \\ ${ }^{5}$ Pascasarjana S2 Pendidikan IPA FKIP, Universitas Bengkulu \\ Email: ${ }^{1}$ fahmizal@ugm.ac.id, ${ }^{2}$ tommy.richard.o@mail.ugm.ac.id, ${ }^{3}$ budibm@ugm.ac.id, \\ ${ }^{4}$ maun.budiyanto@ugm.ac.id, ${ }^{5}$ afrizalmayub@unib.ac.id
}

(Naskah masuk: 11 September 2018, diterima untuk diterbitkan: 15 November 2018)

\begin{abstract}
Abstrak
Makalah ini memaparkan perancangan kendali logika fuzzy pada sistem electronic control unit (ECU) air conditioner mobil. Salah satu kendala pada ECU mobil adalah kerusakan pada sistem air conditioner. Bila ini terjadi umumnya pengguna mobil mengganti sistem ECU secara keseluruhan. Namun pada makalah ini, penulis meracang sistem ECU yang secara khusus digunakan untuk sistem air conditioner mobil. Sistem yang dirancang menggunakan sensor DS18B20 waterproof untuk mendeteksi suhu evaporator mobil. Selanjutnya, nilai suhu tersebut digunakan sebagai masukan logika fuzzy yang terdiri dari pembacaan suhu sekarang dan suhu terakhir dalam mengatur kecepatan putar kipas motor DC atau fan exhausting dan waktu switching magnetic clutch compressor menyala. Penyelesaian hubungan relasi masukan fuzzy diselesaikan menggunakan aturan Mamdani dan keluaran dari logika fuzzy diselesaikan menggunakan metode weight average (WA). Dari hasil pengujian diperoleh bahwa kendali logika fuzzy yang diaplikasikan pada rancangan sistem air conditioner mampu mengendalikan kecepatan fan exhausting secara halus dan responsif.
\end{abstract}

Kata kunci: Electronic Control Unit (ECU), Kendali Logika Fuzzy, Air Conditioner.

\section{Fuzzy Logic Control in an Electronic Control Unit (ECU) Car Air Conditioner System}

\begin{abstract}
This paper describes the design of fuzzy logic controls in the system of electronic control unit (ECU) of car air conditioner. One obstacle in the car ECU is damage to the air conditioner system. If this happens generally car users change the whole ECU system. But in this paper, the authors form the ECU system which is specifically used for car air conditioner systems. The system is designed using a DS18B20 waterproof sensor to detect the temperature of the car's evaporator. Furthermore, the temperature value is used as a fuzzy logic input consisting of reading the current temperature and the last temperature in adjusting the rotating speed of the DC motor fan or exhausting fan and when the switching magnetic clutch compressor is on. Completion of fuzzy input relations is solved using Mamdani rules and the output of fuzzy logic is solved using the weight average (WA) method. From the test results it was found that the fuzzy logic control applied to the design of the air conditioner system was able to control the speed of the exhausting fan in a smooth and responsive manner.
\end{abstract}

Keywords: Electronic Control Unit (ECU), Fuzzy Logic Controller, Air Conditioner.

\section{PENDAHULUAN}

Pada dasarnya perkembangan teknologi otomotif berpokok pada tiga hal yaitu keamanan, kenyamanan, dan ramah lingkungan. Salah satu hal yang dapat meningkatkan tingkat kenyamanan saat berkendara adalah adanya sistem air conditioner pada kendaraan mobil (Purnawan dan Wirawan, 2010). Air conditioner adalah suatu sistem untuk mengatur suhu dan juga kelembaban pada suatu ruangan. Air conditioner digunakan untuk mengatur suhu udara yang mencangkup sirkulasi udara, kelembaban udara, dan kebersihan udara (Alfiyan, 2015). Penggunaan air conditioner pada kendaraan mobil sangat diperlukan agar pengemudi dan juga penumpang memperoleh kenyamanan dalam berkendara. Selain itu dari sisi keamanan, pengendara dan penumpang lebih terjamin keamanannya karena pintu dan jendela mobil harus tertutup rapat ketika air conditioner dihidupkan, hal tersebut menyebabkan penggunaan air conditioner pada kendaraan mobil semakin penting (Aynur, 2010).

Udara panas yang ada di dalam ruangan kendaraan mobil ketika mobil berada di bawah terik matahari dapat menjadi salah satu penyebab adanya korban yang meninggal. Udara panas yang tidak bisa dibuang dan disirkulasikan dengan udara dingin ketika terjadi kerusakan pada sistem air conditioner pada kendaraan mobil menyebabkan udara di dalam 
ruangan kendaraan mobil bercampur dengan gas karbon monoksida hasil pembakaran pada mesin kendaraan mobil. Akibatnya adalah sistem pernafasan pada manusia menjadi terganggu, yang berujung pada kematian. Pada makalah ini dilakukan penelitian sebagai salah satu bentuk inovasi untuk mengurangi angka kematian pada manusia akibat udara panas yang tidak dapat disirkulasikan dengan udara dingin dan membuang udara panas yang bercampur dengan gas karbon monoksida dengan menggunakan kipas motor DC sebagai miniatur dari fan exhausting.

Pada kendaraan mobil, pengkondisian air conditioner meliputi pada proses pendinginan yaitu dengan cara pemanasan atau penambahan uap air dan pendinginan atau pengurangan kandungan uap air (Kobayashi dkk, 1990). Beberapa tahun belakangan ini, banyak kejadian yang dialami oleh beberapa montir atau teknisi yang secara khusus menangani masalah sistem air conditioner pada kendaraan mobil. Beberapa komponen mengalami disfungsi akibat adanya kerusakan pada sistem pendingin yang secara keseluruhan pusat pengaturannya berada pada electronic control unit (ECU) di kendaraan mobil. Sebagai contohnya, kemampuan kipas pendingin condensor yang tidak dapat berputar sesuai dengan kapasitasnya dalam satuan rotation per minutes (RPM). Kemudian tidak berjalannya sistem otomatisasi pada magnetic clutch compressor disaat suhu yang terbaca oleh sensor suhu di dalam evaporator sudah mencapai batas minimalnya.

Penelitian yang dilakukan oleh (Priyojatmiko \& Musafa, 2017) membahas perancangan sistem pendingin mesin mobil menggunakan pengendali logika fuzzy. Sistem akan mengatur kecepatan putar kipas radiator disesuaikan dengan kondisi suhu air radiator dan suhu ruang mesin yang dideteksi menggunakan sensor PT100. Namun pada penelitian tersebut belum membahas perancangan dan desain sistem ECU beserta implementasinya sehingga belum ada hasil pengujian yang diterapkan pada mobil.

Makalah ini memaparkan hasil penelitian untuk merancang dan mengimplementasikan sistem ECU yang digunakan untuk mengendalikan sistem air conditioner pada kendaraan mobil. Sistem yang dirancang menggunakan sensor DS18B20 waterproof untuk mendeteksi suhu evaporator mobil dan sensor DHT-22 yang digunakan untuk memberikan informasi suhu pada ruangan mobil. Selanjutnya, nilai suhu hasil pembacaan sensor DS18B20 waterproof digunakan sebagai masukan logika fuzzy yang terdiri dari pembacaan suhu sekarang dan suhu terakhir dalam mengatur kecepatan putar kipas motor DC atau fan exhausting dan waktu switching magnetic clutch compressor menyala.

\section{SISTEM AIR CONDITIONER}

\subsection{Sistem Air Conditioner pada Mobil}

Air conditioner adalah suatu sistem yang mampu mengkondisikan suhu udara yang digunakan untuk pendinginan maupun pemanasan tergantung pada sifat udara pada waktu tertentu. Sistem air conditioner merupakan bagian dari sistem yang ada pada mobil untuk mencapai kenyamanan dalam berkendara (Pratama, 2015). Penggunaan air conditioner pada kendaraan mobil sangat diperlukan agar pengemudi dan juga penumpang guna memperoleh kenyamanan dalam berkendara. Agar dapat mendukung sistem air conditioner pada kendaraan mobil maka dibutuhkan refrigerant (zat pendingin) (Keating dan Staudt, 1996). Komponen utama yang ada pada sistem air conditioner pada mobil yaitu compressor, condenssor, receifer/dryer, expansion valve dan evaporator seperti yang disajikan pada Gambar 1.

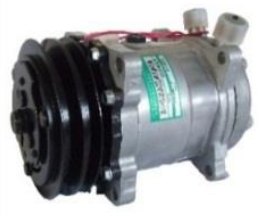

(a). Compressor

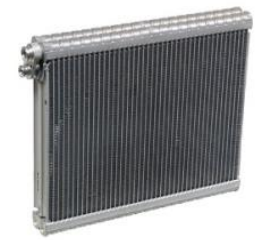

(b). Condenssor

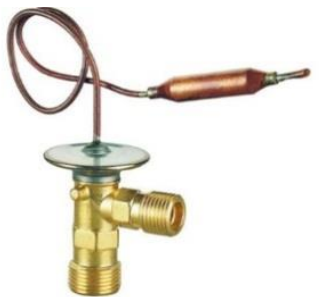

(d). Expansion valve

Gambar 1. Komponen utama yang ada pada sistem air conditioner pada mobil.

\subsection{Electronic Control Unit}

Electronic control unit (ECU) berfungsi sebagai sirkuit elektronik utama pada sebuah mobil. ECU seperti yang diperlihatkan pada Gambar 2 berperan sebagai central controller atau jika pada komputer seperti central processing unit (CPU) yang mengendailkan fungsi hardware (Kaiser, 2015). Pada mobil, perangkat keras yang dikendalikan berupa aktuator yang bekerja menggantikan sistem mekanis seperti injektor, variable valve timing (VVT), electric fan, dan lainnya. ECU merupakan unit controller yang mengatur kinerja suatu sirkuit elektrikal keseluruhan pada sebuah mobil. 


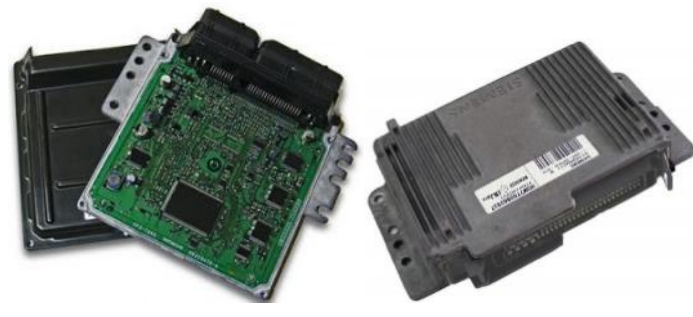

Gambar 2. Contoh Electronic control unit (ECU) pada mobil.

\section{PERANCANGAN SISTEM AIR CONDITIONER PADA KENDARAAN MOBIL}

Secara menyeluruh sistem ECU air conditioner pada kendaraan mobil meliputi rancangan bagian perangkat keras (hardware) dan rancangan pada bagian perangkat lunak (software) seperti yang disajikan pada Gambar 3.

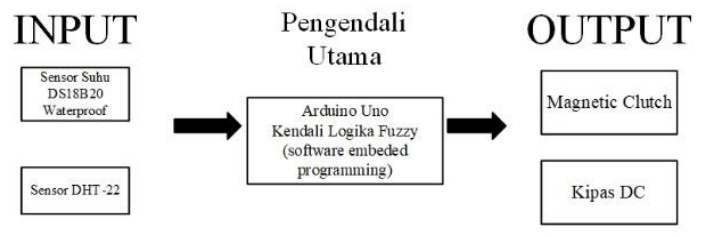

Gambar 3. Blok sistem rancangan ECU secara keseluruhan.

\subsection{Perancangan Mekanika}

Pada sistem perancangan mekanik, desain kemasan cover ECU disajikan pada Gambar 4. Komponen yang terdapat dalam kemasan cover ini lebih jelas disajikan pada Gambar 5.
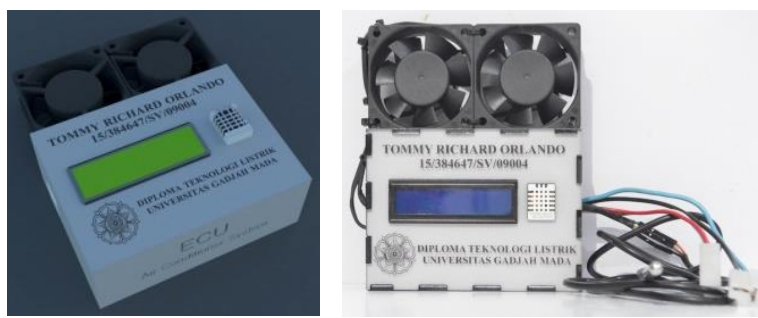

Gambar 4. Desai cover rancangan ECU.

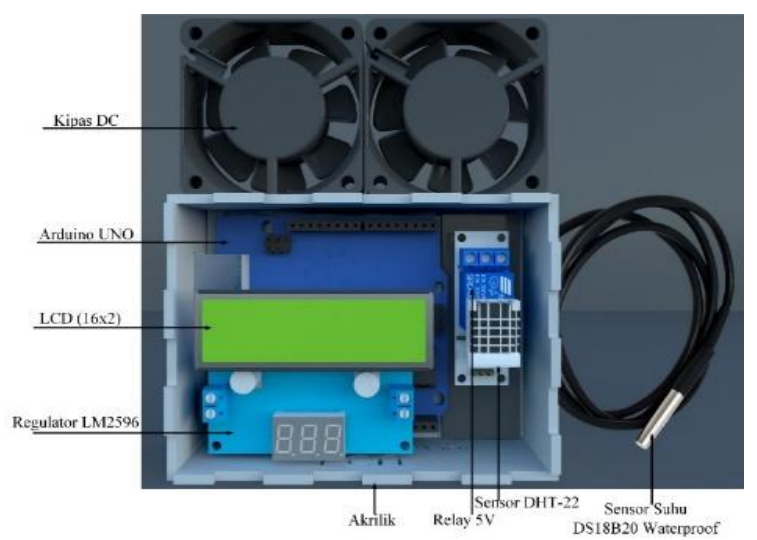

Gambar 5. Detail komponen rancangan ECU.

\subsection{Perancangan Elektronika}

Perancangan sistem elektronika ECU menggunkan Arduino UNO sebagai pengendali utama, sensor DS18B20 waterproof sebagai sensor pendeteksi suhu pada evaporator dan sensor DHT22 sebagai sensor pendeteksi suhu ruangan dan kelembaban udara di dalam ruangan mobil. Rancangan sistem elektronika secara keseluruhan ditunjukkan pada Gambar 6, dimana terdapat dua buah sensor sebagai input, Arduino UNO sebagai CPU yang juga tertanam sebuah kendali logika fuzzy didalamanya untuk mengatur dua buah output berupa magnetic cluth compressor dan kipas motor DC atau fan exhausting.

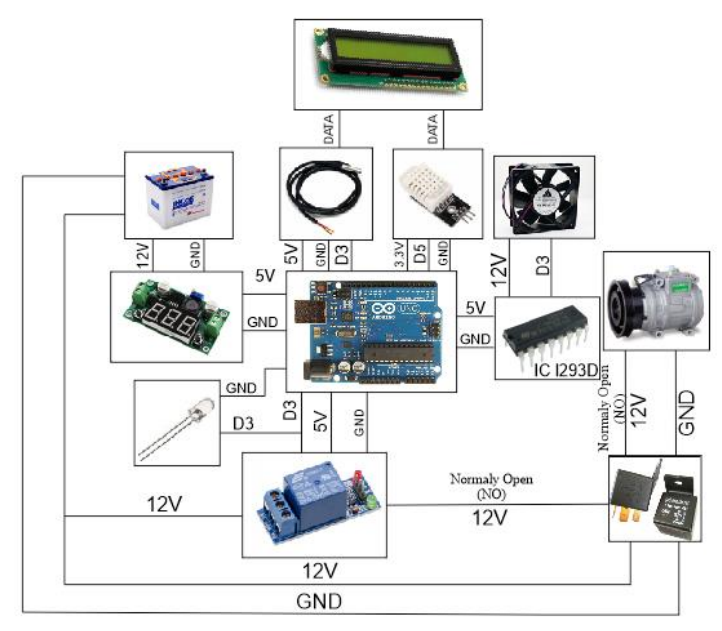

Gambar 6. Diagram blok sistem elektronis ECU.

Pada penelitian ini menggunakan DS18B20 waterproof sebagai sensor suhu yang memiliki kemampuan untuk mengukur suhu pada kisaran $55^{\circ} \mathrm{C}$ sampai $125^{\circ} \mathrm{C}$. Selain itu, sensor ini bekerja dengan faktor kesalahan sebesar $\pm 0,5^{\circ} \mathrm{C}$ pada kisaran suhu $-10^{\circ} \mathrm{C}$ sampai $85^{\circ} \mathrm{C}$ (Resolution, 2008).

Selanjutnya, hasil pembacaan sensor suhu akan diproses dan digunakan untuk menggerakkan aktuator berupa switching magnetic clutch compressor (kompressor) dan kipas motor DC atau fan exhausting yang dikendalikan dengan logika fuzzy. Untuk menggerakkan kompressor maka pada pembacaan sensor akan diberikan batas (range). Ketika suhu yang terbaca bernilai kurang dari sama dengan $7^{\circ} \mathrm{C}$ maka aktuator akan mati dan relay magnetic clutch akan bernilai " 0 " sedangkan jika lebih dari sama dengan $9^{\circ} \mathrm{C}$ maka aktuator akan menyala dan relay magnetic clutch akan bernilai "1". Diagarm alir Gambar 7 merupakan aliran proses dalam memberi batas nilai dan kondisi pada aktuator magnetic clutch compressor.

\subsection{Perancangan Sistem Kendali Fuzzy}

Logika fuzzy yang diimplementasikan pada sistem ECU air conditioner ditanam kedalam Arduino UNO dengan istilah embeded fuzzy, artinya semua tahapan fuzzy diolah komputasinya dalam sebuah chip (Fahmizal, 2017). Diagram blok sistem 
kendali fuzzy yang diimplementasikan pada sistem ECU ini disajikan pada Gambar 8 dan diagram alir sistem secara keseluruhan disajikan pada Gambar 9. Pada sistem rancangan ECU ini, variable masukan untuk fuzzifikasi diperoleh dari hasil pembacaan sensor DS18B20 waterproof.

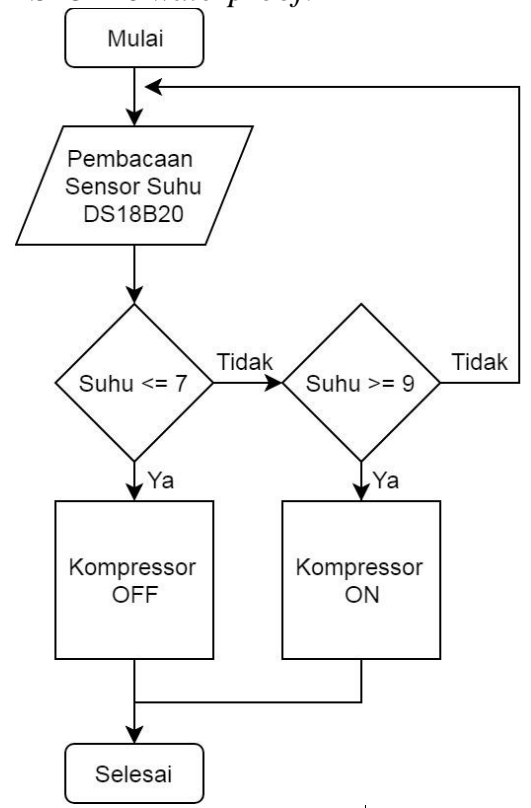

Gambar 7. Diagram alir pembacaan suhlu, pembatasan nilai dan kondisi aktuator magnetic clutch compressor.

Pembacaan suhu saat ini disimpan dalam variable suhu dan pembacaan suhu lampau disimpan dalam variable dsuhu. Lebih lanjut, suhu dan dsuhu ini yang kemudian menjadi masukan ke dalam fuzzifikasi dan merupakan fungsi keanggotaan masukan. Adapun penjelasan dari fungsi keanggotaan masukan dijabarkan sebagai berikut:

a. Fungsi keanggotaan suhu terdiri dari Sangat Dingin, Agak Dingin, dan Dingin. Nilai dari masing-masing fungsi keanggotaan Suhu disajikan pada Gambar 10.

b. Fungsi keanggotaan dsuhu terdiri dari Sangat Dingin, Agak Dingin, dan Dingin. Nilai dari masing-masing fungsi keanggotaan dsuhu disajikan pada Gambar 11.

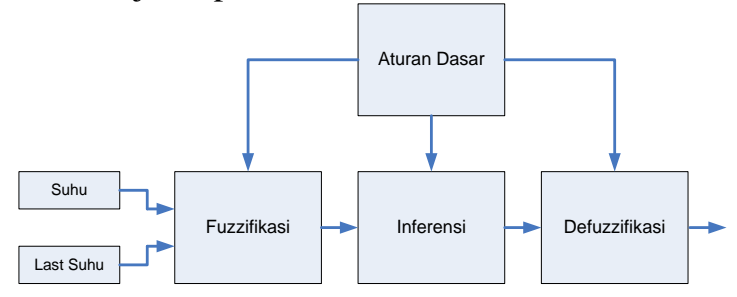

Gambar 8. Diagram blok sistem kendali fuzzy.

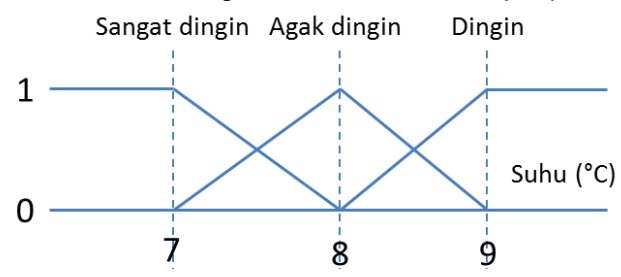

Gambar 10. Himpunan keanggotaan fuzzifikasi suhu.

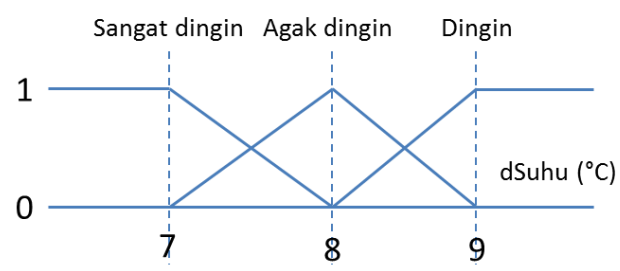

Gambar 11. Himpunan keanggotaan fuzzifikasi dsuhu.

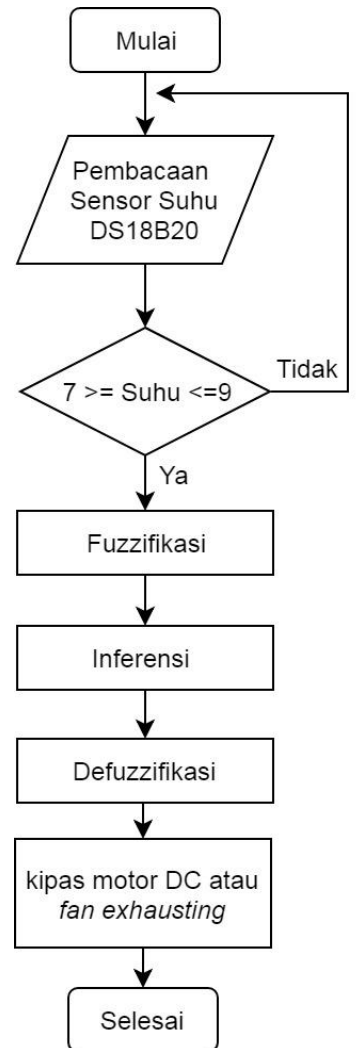

Gambar 9. Diagram alir sistem secara keseluruhan.

Setelah didapatkan nilai linguistik berupa derajat keanggotaan dari setiap fungsi, selanjutnya nilai linguistik tersebut akan diolah pada tahapan proses inferensi. Dari fungsi keanggotaan fuzzifikasi yang terdiri dari tiga derajat keanggotaan maka untuk aturan dasar terdiri dari 9 aturan, dimana aturan tersebut antara lain dijelaskan pada Tabel 1 dengan mengacu pada aturan MacVicar Whelan. Berdasarkan daftar aturan tersebut maka dibentuk tabel komposisi aturan yang menjadi acuan implikasi dari masukan himpunan fuzzy suhu dan dsuhu. Aturan fuzzy yang digunakan menggunakan inferensi dengan metode Mamdani (Fahmizal, 2018) seperti yang dijelaskan pada Persamaan (1).

$$
\mu_{y}(k)=\max \left[\min \left\{\mu_{u}(k), \mu_{r}(\operatorname{suhu}(i), d \operatorname{suhu}(j))\right\}\right]
$$

Tabel 1. Tabel aturan fuzzy mengadopsi konfigurasi dari MacVicar Whelan.

$$
\text { suhu }
$$

\begin{tabular}{|c|c|c|c|}
\hline & lambat & lambat & sedang \\
\hline & lambat & sedang & cepat \\
\hline & sedang & cepat & cepat \\
\hline
\end{tabular}


Nilai hasil pemetaan dari inferensi fuzzy tersebut akan diteruskan menuju tahap terakhir pada kendali logika fuzzy. Pada tahap ini, nilai keluaran inferensi akan diubah kembali menjadi nilai krisp agar dapat diimplementasikan kembali pada aktuator. Metode yang digunakan adalah weight average (WA) seperti yang dijelaskan pada Persamaan (2). Untuk mengubah nilai linguistik tersebut diperlukan fungsi yang disesuaikan dengan rentang yang diperlukan oleh aktuator. Pada penelitian ini, tahapan defuzifikasi menggunakan singleton sebanyak tiga buah seperti yang disajikan pada Gambar 12. Nilai keluaran dari defuzzifikasi inilah yang digunakan sebagai penentu nilai kecepatan putar pada kipas motor DC atau fan exhausting berdasarkan nilai suhu pada evaporator.

$$
\begin{aligned}
& W A=\frac{\mu(k 1) \times k 1+\mu(k 2) \times k 2+\mu(k 3) \times k 3}{\mu(k 1)+\mu(k 2)+\mu(k 3)} \\
& \begin{array}{cc|c|c}
{ }^{\text {lambat }} & & & \\
& & & \\
0 & 125 & & \text { PWM } \\
\hline
\end{array}
\end{aligned}
$$

Gambar 12. Himpunan keanggotaan defuzzifikasi kipas motor DC atau fan exhausting.

\subsection{Rancangan Simulasi Kendali Logika Fuzzy pada MatLab}

Gambar 13 merupakan tampilan toolbox fuzzy dalam lembar kerja Matlab. Untuk menambah jumlah masukannya, dilakukan dengan cara klik "Edit" kemudian pilih "Add Variable" lalu pilih "Input". Gambar 14 merupakan data fuzzifikasi nilai suhu dan nilai dsuhu dimana rentang nilai yang dimasukan antara $5^{\circ} \mathrm{C}$ hingga $10^{\circ} \mathrm{C}$ menyesuaikan data fuzzifikasi suhu dan dsuhu. Bentuk fungsi keanggotaan fuzzifikasi dirancang dalam bentuk trapesium (trapmf), dan segitiga (trimf).

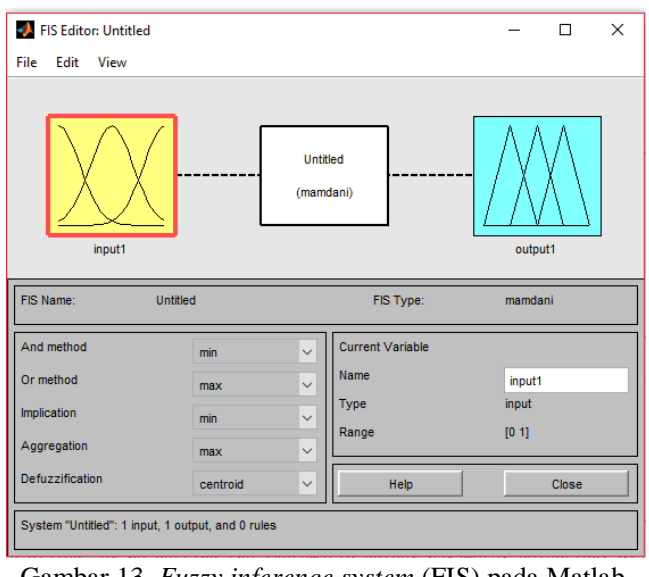

Gambar 15 merupakan data defuzzifikasi nilai pulse width modulation (PWM) dari kipas motor DC atau fan exhausting dengan tiga buah singleton.
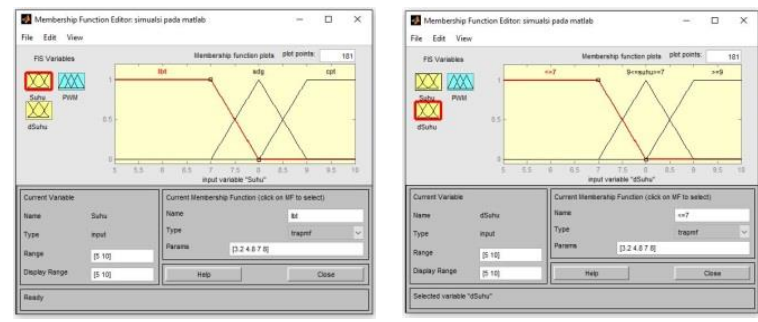

Gambar 14. Fuzzifikasi suhu dan dsuhu pada FIS editor.

Gambar 16 merupakan aturan dasar fuzzy yang digunakan untuk menentukan hasil keluaran sesuai dengan nilai suhu dan dsuhu yang dimasukkan. Aturan tersebut dibuat sesuai dengan aturan fuzzy yang telah ditetapkan sesuai dengan Tabel 1. Untuk membuat aturan tersebut, dapat dilakukan dengan cara klik "Add rule" kemudian masukkan aturan fuzzy sesuai dengan yang sudah ditetapkan seperti yang disajikan pada Gambar 16.

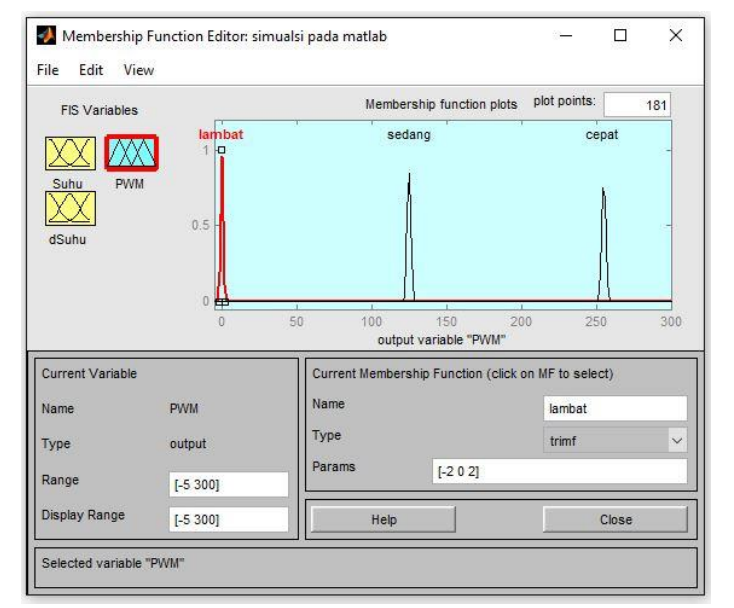

Gambar 15. Defuzzifikasi PWM kipas motor DC pada FIS editor.

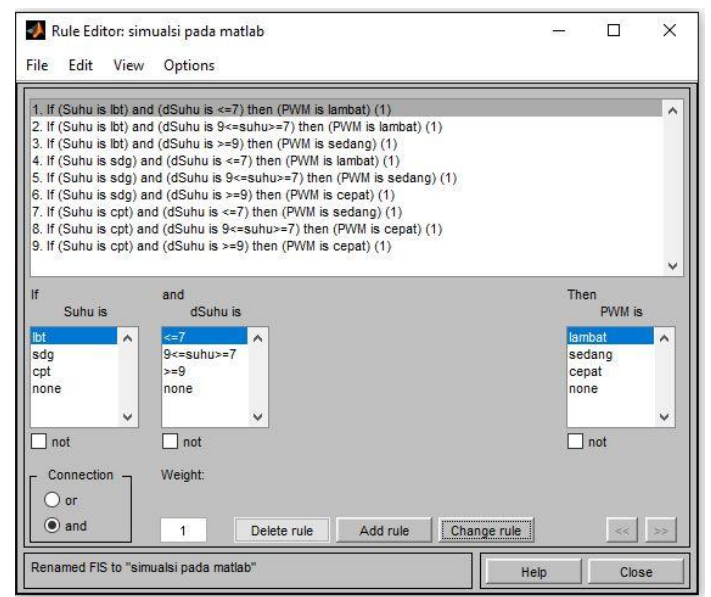

Gambar 16. Memasukan aturan dasar fuzzy pada FIS editor.

Gambar 17 merupakan hasil keluaran dari perhitungan fuzzy berupa nilai PWM dari kipas motor DC atau fan exhausting. Pada blok input, nilai suhu dan dsuhu dapat diubah sesuai dengan yang diinginkan untuk mengetahui nilai keluaran PWM. Sebagai contohnya pada Gambar 17, diketahui ketika nilai suhu sama dengan 9.24 dan nilai dsuhu sama dengan 7.07 maka nilai keluaran PWM 
menurut hasil perhitungan sesuai aturan dasar yang telah ditentukan yaitu 141 .

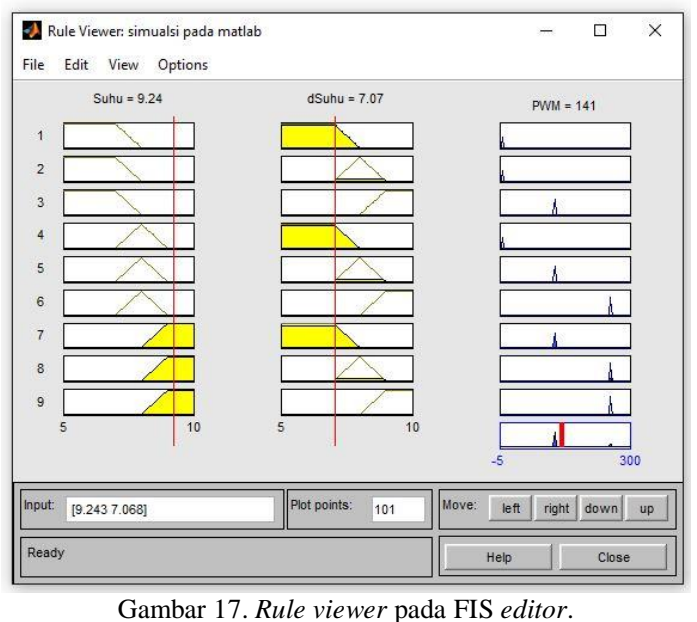

\section{PENGUJIAN DAN PEMBAHASAN}

\subsection{Pengujian Pembacaan Sensor Suhu DS18B20 Waterproof}

Pengujian pembacaan sensor DS18B20 waterproof dilakukan untuk mengetahui tingkat keakurasian, tingkat sensitivitas dan tingkat fungsionalitas. Berdasarkan data nilai suhu hasil pembacaan dari sensor DS18B20 waterproof dan hasil pengukuran menggunakan termometer digital serta termometer analog, dapat diketahui bahwa data nilai suhu yang didapatkan dari hasil pembacaan sensor DS18B20 waterproof lebih akurat dari pada data suhu yang didapatkan dari hasil pengukuran menggunakan termometer digital maupun termometer analog. Berdasarkan datasheet dari sensor DS18B20 waterproof, sensor tersebut memiliki tingkat kesalahan sebesar $\pm 0.5 \%$ pada pembacaan suhu dengan rentang antara $-10^{\circ} \mathrm{C}$ hingga $85^{\circ} \mathrm{C}$, sehingga pembacaan nilai suhu dari sensor tersebut lebih akurat. Nilai suhu hasil pembacaan dan pengukuran pada evaporator disajikan dalam bentuk grafik seperti yang ditunjukkan pada Gambar 18.

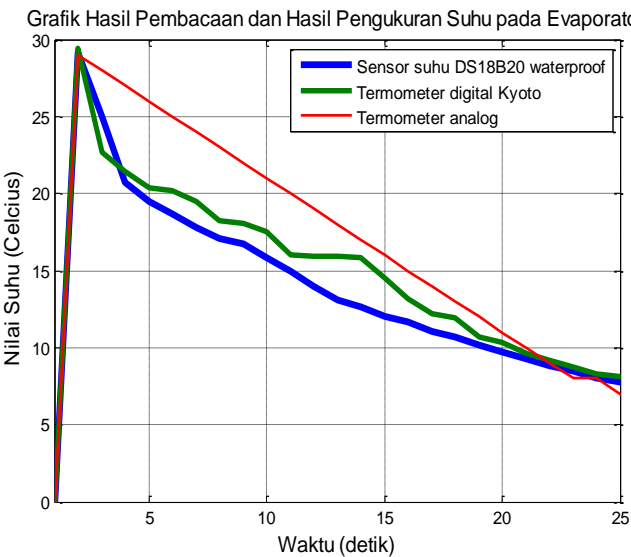

Gambar 18. Grafik hasil pembacaan dan pengukuran suhu pada evaporator.

\subsection{Pengujian Sistem Kendali Logika Fuzzy}

Pengujian sistem kendali logika fuzzy dilakukan pada kendaraan mobil TOYOTA KIJANG EXTRA keluaran tahun 1989 yang sudah dilengkapi dengan sistem air conditioner seperti yang diperlihatkan pada Gambar 19. Pengujian dilakukan dengan cara membandingkan kecepatan putar kipas motor DC atau fan exhausting terhadap perubahan nilai suhu dan dsuhu yang terbaca oleh sensor pada tiap detiknya. Gambar 20 menyajikan hasil pembacaan sensor suhu dan dsuhu. Kendali logika fuzzy ini bekerja ketika magnetic cluch diaktikan sesuai pada suhu yang terbaca oleh sensor suhu DS18B20 waterproof $>=7.00{ }^{\circ} \mathrm{C}$ hingga $<=9.00{ }^{\circ} \mathrm{C}$. Bila diperhatikan Gambar 21, saat detik ke- 20 kecepatan putar kipas motor DC mulai melambat secara halus hingga ke detik 55. Sedangkan grafik hasil nilai PWM kecepatan kipas motor DC tanpa logika fuzzy disajikan pada Gambar 22.

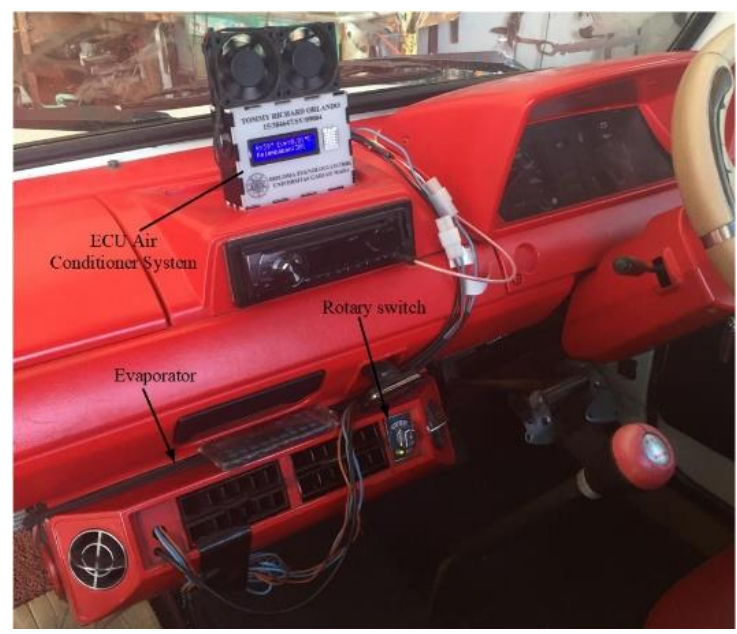

Gambar 19. Implementasi ECU air conditioner pada kendaraan mobil.

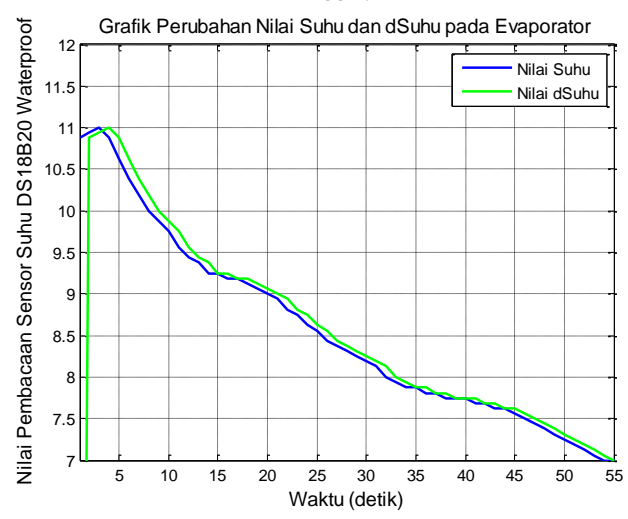

Gambar 20. Grafik pembacaan nilai suhu dan dsuhu.

Berdasarkan data grafik hasil pengujian menggunakan sistem kendali logika fuzzy yang diperlihatkan pada Gambar 21, dapat diketahui bahwa perubahan nilai kecepatan putar kipas motor DC ketika menggunakan sistem kendali logika fuzzy terlihat lebih runtut dan stabil terhadap perubahan nilai suhu yang terbaca oleh sensor DS18B20 waterproof. Sedangkan berdasarkan data grafik dari 
hasil pengujian tanpa menggunakan sistem kendali logika fuzzy seperti yang diperlihatkan Gambar 22, dapat diketahui bahwa perubahan nilai kecepatan putar kipas motor DC terhadap perubahan nilai suhu yang terbaca oleh sensor DS18B20 waterproof terlihat lebih kaku dan kurang terlihat runtut peruahan nilai kecepatan putarnya pada setiap detiknya. Hasil penelitian ini juga telah dipublish dalam bentuk channel video YouTube pada alamat http://youtu.be/RB_gQwXclWk.

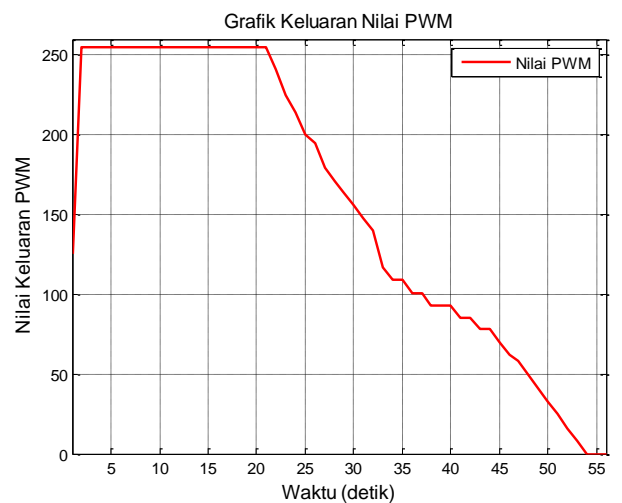

Gambar 21. Grafik hasil kecepatan putar motor DC menggunakan sistem kendali logika fuzzy.

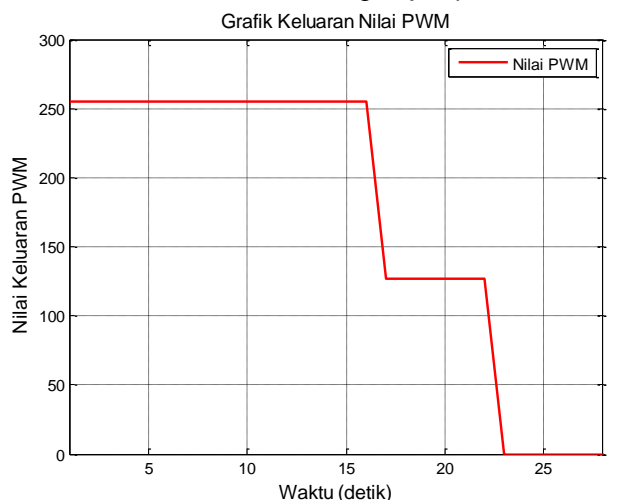

Gambar 22. Grafik hasil kecepatan putar motor DC tanpa menggunakan sistem kendali logika fuzzy.

\section{KESIMPULAN}

Dari serangkaian pengujian dan analisis yang telah dilakukan pada perancangan ECU pada penelitian ini, maka dapat disimpulkan bahwa penggunaan sensor DS18B20 waterproof disarankan karena memiliki nilai pembacaan yang lebih akurat dengan tingkat kesalahan $0.5 \%$ pada rentang suhu $10{ }^{\circ} \mathrm{C}$ hingga $85{ }^{\circ} \mathrm{C}$. Rancangan sistem ECU telah berhasil dirancang dan diimplementasikan menggunakan sistem kendali logika fuzzy. Respon kipas motor DC atau fan exhausting terhadap perubahan nilai suhu dan dsuhu dapat dilihat secara visual bahwa hasil pergerakannya halus. Setelah sistem ECU air conditioner ini dilengkapi dengan kendali logika fuzzy mampu meningkatkan kualitas hasil pergerakan kipas motor DC atau fan exhausting lebih halus bila dibanding dengan tidak menggunakannya.

\section{DAFTAR PUSTAKA}

ALFIYAN, M.R., 2015. Identifikasi Sistem AC (Air Conditioner) pada Toyota Kijang Innova ITR-FE tipe $G$ tahun 2005. Doctoral dissertation, Universitas Negeri Semarang.

AYNUR, T. N. (2010). Variable refrigerant flow systems: A review. Energy and Buildings, 42(7), 1106-1112.

FAHMIZAL, DEWANTAMA, G. Y., PRATAMA, D. B., FATHUDDIN, F., \& WINARSIH. 2018. Rancang Bangun Sistem Penstabil Kamera (Gimbal) dengan Logika Fuzzy untuk Pengambilan Gambar Foto dan Video. Jurnal Teknologi Informasi dan Ilmu Komputer, 5(3), 277-286.

FAHMIZAL, ARROFIQ, M., \& MAYUB, A. 2017. Logika Fuzzy pada Robot Inverted Pendulum Beroda Dua. Jurnal Teknologi Informasi dan Ilmu Komputer, 4(4), 244-252.

KAISER, M. 2015. Electronic control unit (ECU). In Gasoline Engine Management (pp. 254259). Springer Vieweg, Wiesbaden.

KEATING, M. K., \& STAUDT, F. J. 1996. HVAC Control System and Method. U.S. Patent No. 5,544,809. Washington, DC: U.S. Patent and Trademark Office.

KOBAYASHI, T., OTSUKA, N., THOMPSON, P., \& STRATTON, L. J. 1990. U.S. Patent No. 4,948,040. Washington, DC: U.S. Patent and Trademark Office.

PRATAMA, A. W. 2015. Troubleshooting Sistem Air Conditioner Pada Mobil Toyota Kijang Innova 1TR-FE (Doctoral dissertation, Universitas Negeri Semarang).

PRIYOJATMIKO, P., \& MUSAFA, A. (2017, October). Rancang Bangun Sistem Pendingin Mesin Mobil Menggunakan Pengendali Logika Fuzzy. In Prosiding Seminar Nasional Teknoka (Vol. 1, pp. 121-131).

PURNAWAN, A., \& WIRAWAN, I. K. 2010. Analisa Performansi Sistem Air Conditioning Mobil tipe ET 450 dengan Variasi Tekanan Kerja Kompresor. Jurnal Energi Dan Manufaktur, vol. 4, no. 1, pp. 26-30.

RESOLUTION, D. P. 2008. 1-Wire Digital Thermometer. Data Sheets. DALLASMAXIM.[dostęp 11-07-2006]. Dostępny w Internecie: http://www. maximic. com/quick_view2. cfm/qv_pk/2813. 
Halaman ini sengaja dikosongkan 